\title{
Erratum to: Adding a newly trained surgeon into a high-volume robotic prostatectomy group: are outcomes compromised?
}

Luchen Wang ${ }^{1} \cdot$ Mireya Diaz $^{2} \cdot$ Hans Stricker ${ }^{2} \cdot$ James O. Peabody $^{2} \cdot$ Mani Menon ${ }^{2} \cdot$ Craig G. Rogers ${ }^{2}$

Published online: 14 October 2016

(C) Springer-Verlag London 2016

\section{Erratum to: J Robotic Surg}

DOI 10.1007/s11701-016-0615-7

Unfortunately, last word of the title ("compromised") was missing in the original online publication of this article.

The correct article title is given here, and the article itself has been corrected.

Adding a newly trained surgeon into a high-volume robotic prostatectomy group: are outcomes compromised?

The online version of the original article can be found under doi:10.1007/s11701-016-0615-7.

\section{Craig G. Rogers}

crogers2@hfhs.org

1 Wayne State University School of Medicine,

540 East Canfield St, Detroit, MI 48201, USA

2 Vattikuti Urology Institute, Henry Ford Health System, 2799 West Grand Blvd, Detroit, MI 48202, USA 